\title{
Process flow of spray pyrolysis technique
}

\author{
S.M.Sabnis ${ }^{1}$, Prakash A. Bhadane ${ }^{2}$, P. G. Kulkarni ${ }^{3}$ \\ 1(Department: Physics, Saraswati college of Engineering, plot no-46, sector-05, behind MSEB sub \\ station,Kharghar, Navi Mumbai-410210, Maharashtra, India,/University Name :-Author 1 is Ph.D. Scholar of \\ Shri JJT University, Vidyanagari, Churu Jhunjhunu Road, Chudela, District-Jhunjhunu, Rajasthan-333001.
}

\begin{abstract}
The chemical spray pyrolysis technique (SPT) has been, throughout last 3 decades, one amongst the most important techniques to deposit a large type of materials in thin film kind. The prime requisite for getting sensible quality thin film is that the optimization of propaedeutic conditions viz. substrate temperature, spray rate, concentration of solution etc. However, in recent years a stress has been given to a range of atomization techniques like supersonic nebulisation, improved spray reaction, corona spray transformation, electricity spray transformation and microchip primarily based spray transformation. This is often the foremost crucial parameter because it permits management over the scale of the droplets and their distribution over the preheated substrates. An intensive review of thin film materials ready throughout the last ten years is given to demonstrate the flexibility of the chemical SPT. the assorted conditions to get thin films of metal compound, metallic mineral oxides, binary, ternary and quaternary chalcogenides and superconducting oxides are given. The consequences of precursor, dopants, substrate temperature, post tempering treatments, answer concentration etc., on the physico-chemical properties of those films are given likewise. It's discovered that the properties of thin films rely significantly on the propaedeutic conditions. The properties of the thin film will be simply tailored by adjusting or optimizing these conditions that successively are appropriate for a specific application.
\end{abstract}

\section{INTRODUCTION}

Numerous materials are ready within the kind of thin films over a century attributable to their potential technical price and scientific curiosity in their properties. They need terribly wide selection of applications and extend from micrometer dots in electronics to coatings of many sq. meters on window glasses. Varieties of techniques are examined within to explore for the foremost reliable and most cost-effective technique of manufacturing the thin films. These embrace reaction of a gaseous metal film, reactive and nonreactive sputtering techniques, chemical vapor deposition etc. and variety of strategies involving growth from chemical solutions, questionable chemical techniques. Many studies have been done over about three decades on chemical spray pyrolysis (SP) process and preparation of thin films, since the pioneering work by Chamberlin and Skarman [1] in 1966 on cadmium sulphide (CdS) films for star cells. Thereafter, owing to the simplicity of the equipment and sensible productivity of this system on an oversized scale it offered a most attractive means for the formation of thin films of noble metals, metal oxides, mineral oxides, chalcogenides and superconducting compounds. Despite its simplicity, SP contains a range of benefits.

(1) It offers a particularly straightforward way to dope films with just about any component in any proportion by simply adding it in some type to the spray resolution.

(2) not like closed vapor deposition ways, SP doesn't need prime quality targets and/or substrates nor will it need vacuum at any stage, that could be a nice advantage if the technique is to be scaled up for industrial applications. (3) The deposition rate and also the thickness of the films is simply controlled over a good vary by dynamic the spray parameters, therefore eliminating the main drawbacks of chemical ways like sol \pm gel that produces films of restricted thickness.

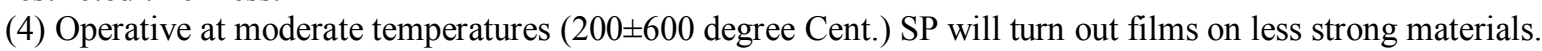

(5) Not like high-powered strategies like frequency electron tube sputtering (RFMS), it doesn't cause native heating that may be prejudicial for materials to be deposited. There are nearly no restrictions on substrate material, dimension or its surface profile.

(6) By dynamic composition of the spray solution throughout the spray method, it is often used to create bedded films and films having composition gradients throughout the thickness.

(7) it's believed that reliable elementary kinetic information are additional seemingly to be obtained on significantly well characterized film surfaces, provided the films area unit quiet compact, uniform which no aspect effects from the substrate occur. SP offers such a chance.

The SP technique is helpful for the assembly of thin films of easy oxides, mixed oxides, bronze mineral sort oxides, group I-VI, II-VI, III-VI, IV-VI, V-VI, VIII-VI binary chalcogenides, cluster I-III-VI, II-II-VI, II-III-VI, II-VI-VI and V-II-VI ternary chalcogenides, adamantine copper compounds like $\mathrm{Cu} 2 \mathrm{ZnSnS} 4 / \mathrm{Se} 4, \mathrm{Cu} 2$ 
$\mathrm{CdSnS} 4 / \mathrm{Se} 4, \mathrm{CuGa} \mathrm{SnS} 4 / \mathrm{Se} 4, \mathrm{Cu} 2 \mathrm{InSnS} 4 / \mathrm{Se} 4, \mathrm{CuIn} 5 \mathrm{~S} 4 / \mathrm{Se} 4$ etc. Recently chemical SP technique has conjointly been with success used for the formation of superconducting chemical compound films. thin films of such metal chemical compound and bronze mineral chemical compound materials ready by SPT have matching properties for wide selection of potential applications [2 \pm 52$]$. Chalcogenide semiconductor compounds of cluster $\mathrm{II} \pm \mathrm{VI}$ and $\mathrm{V} \pm \mathrm{VI}$ have applications in precise temperature management of optical maser diodes, optical sound system, chemistry devices, straingauges and thermo-electrical devices. These thin films have nice technological importance because of their potential applications in picture chemistry cells, star selective and ornamental coatings, optoelectronic devices and thermo-electrical coolers [50 56$]$.

Since the invention of extreme temperature electrical conduction in oxides like $\mathrm{Y}-\mathrm{Ba}-\mathrm{Cu}-\mathrm{O}$, lots of work has been done on their preparation into thin films by SPT. Thin films of those compounds have applications in electronic devices like superconducting quantum interference devices (SQUID) $[5,6]$.

Some review articles referring to spray shift process and also the range of thin films deposited by SPT for varied applications have appeared within the literature. Pamplin gave a review of clear conductors and a listing in a very conference on spray shift [8]. Viguie and spitz have classified chemical spray deposition method consistent with the sort of reaction [9]. Kern and Tracy have rumored on a high-speed production spray shift method for titanium dioxide antireflection coating for chemical element cells. However, a comprehensive review of all doable thin film materials that would be deposited by SP technique for varied industrial applications has not been undertaken up to now.

In this article, the chemical skillfulness of SP technique is incontestable by reviewing the literature on transition metal oxides, metallic mineral kind oxides, binary, ternary and quaternary chalcogenides and superconducting thin films.

A more currentreview (last 10 years) on thin film materialsprepared by SP and advances in the field particularly, diverse atomization techniques areoffered. Some untimely references

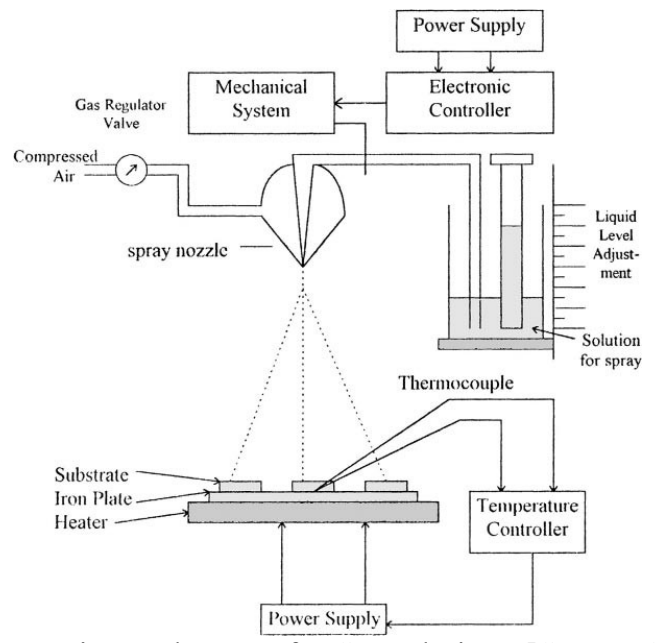

Fig.1. Experimental set-up for SP technique.[Source Online]

are also cited where necessary. As there are as several sets of spraying equipments as there are laboratories, the planning of a typical spray transmutation found out and mechanism of film formation is given, that holds smart for nearly all spraying equipments. An intensive survey on preparation conditions for a good type of thin film materials is conferred. The preparation of those thin films and their physico-chemical properties are mentioned.

\section{FILM FORMATION TECHNIQUE}

In the spray deposition method, a precursor solution is fine by means that of a neutral gas (e.g. nitrogen) so it arrives at the substrate within the style of terribly fine droplets. The constituents react to create a matter onto the substrate. The chemical reactants are selected specified the merchandise aside from the required compound are volatile at the temperature of deposition. Fig. 1 shows a typical spraying system. To measure flow of precursor resolution and air, liquid and gas flow meters are used. The properties of the film rely upon the ion to ion ratio, spray rate, substrate temperature; close atmosphere, carrier gas, drop size and conjointly the cooling rate once deposition. The film thickness depends upon the gap between the spray nozzle and substrate, substrate temperature, the concentration of the precursor solution and therefore the amount of the precursor solution sprayed. The film formation depends on the method of drop landing, reaction and solvent evaporation that are associated with drop size and momentum. a perfect deposition condition is once the drop approaches the substrate even as the solvent is totally removed. Lampkin [10] showed that, betting on drop rate and flow 
direction, a drop can flatten, skip on the surface or hover static Table1 presents the deposition conditions for varied thin film materials ready by using SP technique throughout the last decade.

\subsection{ATOMIZATION TECHNIQUES}

The vital operations for the spray pyrolysis technique are (I) preparation of uniform and fine droplets and (II) the controlled thermal decomposition of those droplets in terms of setting, location and time. Typically commercial nozzle atomizers are used to spray solutions for thin film preparation. However, such nozzle atomizers are neither comfortable to get reproducibly micrometer or submicron size drop nor to manage their size distribution.

Consequently, some new or changed spray atomization techniques are developed recently and used effectively for thin film preparations. A number of them are in brief given below.

\subsubsection{ULTRASONIC NEBULIZED ATOMIZATION}

To obtain uniformly distributed micrometer and sub-micrometer size droplets, a supersonic nebulizer has been used $[2,6]$. Usually the precursor solutions area unit vaporized with a supersonic nebulizer (ultrasonic power of mist generator is regarding $100 \mathrm{~W}$ ) that is operated at a frequency of $2.56 \mathrm{MHz}$. The vapor generated is transported by the carrier gas, air, through a pipe to the heated substrate. To coat an oversized space, the spray jet is scanned unendingly. The precursor answer is reborn into little droplets by the supersonic waves, such droplets have terribly little sizes with a slim size distribution and no inertia in their movement in order that they will be transported the carrier gases with none heating. The solvent vaporizes because the droplets approach the substrate. The pyrolysis of an aerosol, created by the supersonic spraying is thought because the pyrosol method. The advantage during this technique is that the gas rate is freelance of the aerosol rate, that isn't the case with gas spraying.

\subsubsection{IMPROVED SPRAY PYROHYDROLYSIS}

Two necessary conditions permanently quality thin films preparations are to get a mist of the solution with little droplets and their uniform distribution. To fulfill these conditions, a replacement spray and deposition chamber has been developed that improves the selectivity of the droplets that arrive near the substrate. Because of the geometry of the chamber and to the attractive force, that is proportional to $\mathrm{r} 3(\mathrm{r}$ is that the driblet radius), the larger droplets cannot be transported by the carrier gas and so, come to the spray chamber. Totally different system configurations are tried for the formation of excellent quality films. This spray pyrolysis system has the subsequent advantages: (1) smart size selectivity of the droplets, (2) a suppression of vortices owing to the spray gas within the spraying chamber, and (3) reduced convection flow of the recent gas within the deposition chamber [63].

\subsubsection{CORONA SPRAY PYROLYSIS}

The limitation of the traditional pneumatic spray pyrolysis technique is that the low deposition potency, outlined because the ratio of atoms effectively deposited to those provided. Recently, the deposition potency has been improved by the addition of a corona discharge to regulate the transport of aerosol droplets towards the substrate, and potency as nice as eightieth is rumored [4,5]. Corona spray transmutation is often used to manage the trajectories of the individual droplets as long as direct contact with the surface is avoided. This has the potential of raising the potency of film growth. This system has the advantage of giving a lot of control to the appliance of the spray to the substrate because the charged droplets should follow the electrical field lines. It's conjointly been claimed that more economical use of the solution is formed as all droplets strike the surface and none will escape up the vent. The aerosol was generated using a supersonic electrical device vibrating at concerning $200 \mathrm{kc}$ and producing ten millimetre droplets [6]. The electrical device generates an intense supersonic beam that produces a geyser at the surface of the solution used and also the formation of a slender distribution of aerosol droplets. With nitrogen because the carrier gas the aerosol mist is delivered to the spraying chamber through a glass nozzle, a thin however wide stream of mist that can be directed either over or at the heated substrate $(0 \pm 900$ angle). A vent at the opposite end of the heater produces sufficient draft therefore on offer an approximation of streamline flow. The droplets are often electrostatically charged by a knife edge command simply higher than the aerosol stream. At high sharp voltages a corona discharge can occur close to the sharp fringe of the knife and also the resultant ionic current can charge any droplets in its path. the availability voltage ranges from 10 to $30 \mathrm{kv}$. The knife edge is sometimes employed in conjunction with a metal plate to deflect additional charged droplets to the heater [7].

\section{1..4. ELECTROSTATIC SPRAY PYROLYSIS}

A horizontal electricity spray pyrolysis (ESP) discovered with capillary-plate configuration is employed to arrange mineral films. Round stainless-steel disks area unit chosen because the substrate and act as 
the 'plate'. A component is employed to manage the substrate temperature. A positive high voltage up to 12.5 kilovolt was applied to the nozzle (a hollow needle or capillary) through that the precursor resolution is forced to flow, and from that a charged spray is generated. underneath chiefly the electricity force (other forces like, for example, electrical wind play a minor role) the droplets of the spray tend to maneuver to the new substrate wherever transmutation takes place at or close to the surface of the substrate. The nozzle-to-substrate distance is kept little, regarding 6 millimeter [7].

The advantage of this method is that the layer morphology, either dense or porous, might be controlled just by adjusting the deposition time.

\subsection{Microprocessor based spray pyrolysis}

A low cost and proficient electronic control system based on microprocessor has been premeditated and made-up. It regulates the linear simple harmonic activity of a spray nozzle over any preferred length. This array is chieflyimperative for large area deposition of thin films with enormousregularity [8].

\subsection{SnO2}

\section{PREPARATION OF METAL OXIDE THIN FILMS}

Tin compound is one in every of the foremost wide used thin film materials ready by spray shift. Thin films of $\mathrm{SnO} 2$ are ready using $\mathrm{SnCl} 4$ dissolved in a very wide range of solvents. The foremost common appears are to be water [6,9] and alcohols [70土85]. Alcoholic solvents were the foremost most popular owing to their low surface tension and consistency facilitates the formation of little spray droplets whereas its low boiling purpose permits it to be with efficiency off from the deposition chamber within the vapour part. The solvent is created slightly acidic with $\mathrm{HCl}$ (or $\mathrm{HF}$ for halide doping) [7]. Non-aqueous solvents like butyl acetate have additionally been tried [65]. The addition of applicable impurities into these solutions provides the doping, e.g. $\mathrm{SbCl} 3, \mathrm{SnF} 2$ or $\mathrm{HF}[60,75 \pm 80]$. A couple of cases of alternative supply compounds like $\mathrm{SnBrO} 4,(\mathrm{C} 4 \mathrm{H} 9) 4 \mathrm{Sn}$, (NH4)2SnCl6, $(\mathrm{CH} 3 \mathrm{COO}) 2 \mathrm{SnCl} 2$ and $(\mathrm{C} 4 \mathrm{H} 9) 2 \mathrm{SnO}$, were additionally reported within the past.

The adjusted growth of $\mathrm{SnO} 2$ films on a glass substrates from the organotin compounds was investigated by yagi et al. $[1,4]$. A series of organotin compounds with radical teams and/or acetate teams like (C4H9)4Sn (TBT), (C4H9)3, SnOOCCH3 (TBTA) and (C4H9)2 Sn(OOCCH3)2 (DBTDA) were used for the formation of extremely adjusted $\mathrm{SnO} 2$ films [71 \pm 74$]$.

The spray shift of TBT and DBTDA led to the deposition of the (1 110$)$ and (2 000$)$ adjusted SnO2 thin films, severally. Any outstanding most popular orientation wasn't found within the film deposited from TBTA. The expansion of (1 000$),\left(\begin{array}{lll}2 & 0 & 1\end{array}\right)$, or ( $\left.\begin{array}{lll}2 & 1 & 1\end{array}\right)$ plane was increased multifariously, betting on film rate and substrate temperature. The adjusted growth of those thin films happens via 3 stages: (a) formation of $\mathrm{SnO} 2$ nuclei, (b) crystal growth of $\mathrm{SnO} 2$ with most popular orientation and (c) any crystal growth traditional to the surface of the substrate. The radical and acetate teams of the supply compounds expedited the $\left(\begin{array}{lll}1 & 1 & 0\end{array}\right)$ and $\left(\begin{array}{lll}2 & 0 & 1\end{array}\right)$ adjusted growths of $\mathrm{SnO} 2$ thin films, severally. The electrical and optical properties of those films also are delineate [70 75$]$.

The morphological, structural, optical and electrical properties of $\mathrm{SnO} 2$ and $\mathrm{F}: \mathrm{SnO} 2$ thin films obtained by spraying $0.5 \mathrm{M}$ alcoholic solution of $\mathrm{SnCl} 4$ have been studied. Undoped films showed a milky appearance, an electrical resistivity of $30 \times 10-4 \Omega \mathrm{cm}$ and $70 \pm 75 \%$ optical transmittance. Thin films obtained from NH4F solutions at fluorine concentrations in the range $1 \pm 30$ wt.\% showed systematic decrease in the surface particle density and an increase in the transmittance with increasing fluorine concentration, attaining values around $80 \%$. The resistivity decreased to $5 \times 10-4$ for $1 \pm 8$ wt.\% doping range and increased above 9 wt.\% five-fold [7]. The optimum substrate temperature and fluorine to tin atomic ratio in the solution were found to be 450 degree cent; and $0.2 \mathrm{M}$, respectively.

These films exhibited $70 \pm 95 \%$ transmittance in visible range and electrical resistivity of $7.4 \mathrm{~mm}$ [7]. Film thickness, growth rate and grain size increased with deposition time, substrate temperature and amount of hydrochloric acid added to the deposition solution. The crystallite orientations also depended on these variables as well as on solution concentration [7].

The structural and electrical properties of polycrystalline $\mathrm{SnO} 2$ films formed at $3000 \mathrm{C}$ have been investigated in a carrier concentration range of 5 X $1017 \mathrm{~cm}-3<\mathrm{Na} \leq 3 \times 1020 \mathrm{~cm}-3$. For 5 X $1028 \mathrm{~cm}-3$, the resistivity is thermally activated and governed by the barrier effect of grain boundaries which act as carrier traps. For $\mathrm{Na} \geq 6 \times 1018 \mathrm{~cm}-3$, the film resistivity is governed by the properties of the bulk material, the mobility of which is limited at $20 \mathrm{~cm} 2 \mathrm{~V}-1 \mathrm{~S}-1$ because of high density of structural defects [8]. The trajectories of aerosol droplets are examined in an attempt to model tin oxide film growth from $\mathrm{SnCl4}$ [6]. 
Table 1 :Background for preparation of thin films for fuel cell

\begin{tabular}{|c|c|c|c|c|c|}
\hline $\begin{array}{l}\text { Fuel cell } \\
\text { Filmmateri } \\
\text { al }\end{array}$ & Spray solution & $\begin{array}{l}\text { Temperature } \\
\text { (degree cent.) }\end{array}$ & Spray rate & Substrate & References \\
\hline \multicolumn{6}{|c|}{ Super conduction oxides trials for fuel cell implementation } \\
\hline $\begin{array}{l}\mathrm{Y}-\mathrm{Ba} 2- \\
\mathrm{Cu} 3 \mathrm{O} 7-\mathrm{x}\end{array}$ & $\begin{array}{ll}\text { Y2(NO3) } \mathrm{Ba}(\mathrm{NO} 3), & \mathrm{Cu}(\mathrm{NO} 3) 2, \\
\text { glycerol, distilled water } & \end{array}$ & 310 & - & $\begin{array}{l}\text { yttria stabilized } \\
\text { zirconia }\end{array}$ & [web] \\
\hline $\begin{array}{l}\text { AgNO3: } \\
\text { YBa2Cu4 } \\
\text { O8 }\end{array}$ & $\begin{array}{l}\mathrm{Y} 2(\mathrm{NO} 3) 2, \quad \mathrm{Ba}(\mathrm{NO} 3), \\
\text { AgNO3, distilled water }\end{array}$ & 800 & - & $\mathrm{MgO}$ & [web] \\
\hline $\begin{array}{l}\mathrm{Hg}-\mathrm{Ba}-\mathrm{Ca}- \\
\mathrm{Cu}-\mathrm{O}\end{array}$ & $\begin{array}{l}\mathrm{HgCl} 2, \quad \mathrm{Ba}(\mathrm{NO} 3) 2, \quad \mathrm{Ca}(\mathrm{NO} 3) 2, \\
\mathrm{Cu}(\mathrm{NO} 3) 2, \text { isophyl alcohol, [propan- } \\
\text { 2-ol-C(CH3)2 } \mathrm{CHOH}]\end{array}$ & $340 \mathrm{a}(770)$ & & silver & [web] \\
\hline $\begin{array}{l}\mathrm{Hg}-\mathrm{Ba} 2- \\
\mathrm{Ca} 2-\mathrm{Cu} 3- \\
\mathrm{Oy}\end{array}$ & $\begin{array}{l}\mathrm{Ba}(\mathrm{NO} 3) 2, \mathrm{Ca}(\mathrm{NO} 3) 2, \mathrm{Cu}(\mathrm{NO} 3) 2, \mathrm{Hg} \\
\text { vapour, } \\
\text { distilled water }\end{array}$ & $100-130 \mathrm{a}(670)$ & & $\begin{array}{l}\text { SrTiO3 } \\
\text { crystals }\end{array}$ & [web] \\
\hline $\begin{array}{l}\mathrm{Hg} 1- \\
\mathrm{xPbxBa} 2 \mathrm{C} \\
\mathrm{a} 2 \mathrm{Cu} 3 \mathrm{O} 8+ \\
\delta\end{array}$ & $\begin{array}{l}\mathrm{Ba}(\mathrm{NO} 3) 2, \mathrm{Ca}(\mathrm{NO} 3) 2, \mathrm{Cu}(\mathrm{NO} 3) 2 \mathrm{Hg} \\
\text { vapour, } \\
\text { Pbvapour, distilled water }\end{array}$ & 830 & & $\mathrm{MgO}$ & [web] \\
\hline
\end{tabular}

\subsection{Superconducting oxide thin films for fuel cell}

\subsubsection{Y-Ba-Cu-O}

Y-Ba-Cu-O films, $1 \pm 2 \mathrm{~mm}$ thick have been geared up by spraying aqueous-glycerol solutions $(0.1 \mathrm{M})$ of yttrium, barium and copper nitrates onto yttria-stabilized zirconia substrates through an ultrasonic nebulizer. The films were treated at $3500 \mathrm{C}$ substrate high temperature. These films werefurther annealed under argon and $\mathrm{O} 2$ environment at temperatures between 870 and $9700 \mathrm{C}$ for a few minutes. The augmentation rate was about $0.7 \mu \mathrm{m} \mathrm{h}-1$ over an area of $4 \mathrm{~cm} \mathrm{X} 12 \mathrm{~cm}$. It was found that aqueous glycerol nitrate solutions offer better films than aqueous nitrate solutions.

Such films illustrate anintelligent superconducting transition and a $T_{C}$ zero above $70 \mathrm{~K}$, which have a superiorcourse of the crystallite c-axis of orthorhombic arrangementvertical to the substrate exterior. It was concluded that SP procedure is feasible for the groundwork of high quality, reasonably pricedfilms over great areas, on wires, ribbons or fibres [6].

A novelamalgamationcourse for the configuration of high $T_{C}$ superconducting films of $\mathrm{YBa} 2 \mathrm{Cu} 4 \mathrm{O} 8$ onto $\mathrm{MgO}$ substrate has been initiated through the adding up of AgNO3 in apposite solution mixture. The AgNO3 acts as an enhancer catalyst which on dissociation during the film processing at $8000 \mathrm{C}$ supplies active oxygen. The $T_{C}$ (zero) was $70 \mathrm{~K}$ for an $\mathrm{Ag}$ concentration of 0.15 . The optimum $J_{C}$ was found to be $7.5 \mathrm{X} 10-4 \mathrm{~A} \mathrm{~cm}-2$ at $15 \mathrm{~K}[9]$.

\section{CONCLUSIONS}

A survey on obtainable literature on chemical SP technique reveals that it so offers a beautiful methodology to arrange large choice of thin film materials for numerous industrial applications. The standard and properties of thin films rely for the most part on the preparation conditions. Recently, stress given to 2 aspects: (1) atomization techniques to manage the drop size and their distribution a lot of exactly and (2) use of beginning compounds like organotin to get extremely homeward thin films looks brighter. Any efforts are necessary to couple these 2 aspects to get prime quality thin films by spray pyrolysis technique.

\section{REFERENCES}

[1] R.R. Chamberlin, J.S. Skarman, J. Electrochem. Soc. 113 (2000) 86.

[2] Z.M. Jarzebski, J.P. Marton, J. Electrochem. Soc. 123 (2002) 199C, 299C, 333C

[3] D.S. Albin, S.H. Risbud, Adv. Ceram. Mater. 2 (2009) 243.

[4] J.S. Ryu, Y. Watanabe, M. Takata, J. Ceram. Soc. Jpn. 100 (2009) 1165.

[5] C. Agashe, M.G. Takawale, B.R. Marathe, V.G. Bhide, Sol. Energy Mater. 17 (1998) 99.

[6] W. Badawy, F. Decker, K. Doblhoffer, Sol. Energy Mater. 8 (1993) 363.

[7] J.C. Manifacier, J.P. Fillard, J.M. Bind, Thin Solid Films 77 (1991) 67.

[8] B. Drevillon, K. Satytendra, P. Roca, I. Cabarrocas, J.M. Siffert, Appl. Phys. Lett. 54 (1999) 2088.

[9] P. Grosse, F.J. Schmitte, G. Frank, H. Kostlin, Thin Solid Films 90 (1989) 309.

[10] K.L. Chopra, S. Major, D.K. Pandya, Thin Solid Films 102 (1989) 1.

[11] S. Kulaszewicz, I. Lasolka, Cz. Michalski, Thin Solid Films 55 (1979) 283.

[12] K. Sato, Y. Gotoh, Y. Hayashi, K. Adachi, H. Nishimura, Asahi Glass Co. Ltd.Rpts. Res. Lab. 40 (1991) 233. 